Universidad de Lima

Facultad de Psicología

Carrera de Psicología

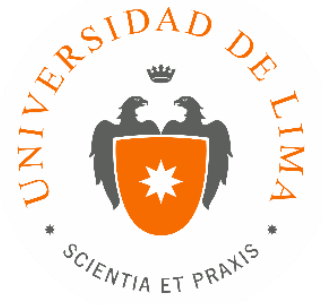

\title{
ENFRENTANDO LA CRISIS DEL MUNDIAL
}

Trabajo de suficiencia profesional para optar el título profesional de Licenciado en Psicología

\section{Brenda Carranza Moyano}

Código 20081280

Lima - Perú

Febrero de 2019 

ENFRENTANDO LA CRISIS DEL MUNDIAL 


\section{TABLA DE CONTENIDO}

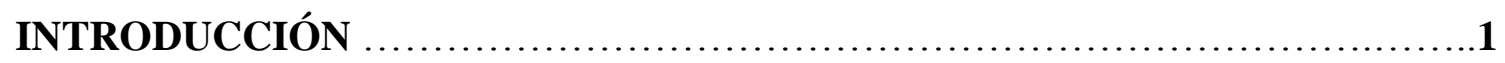

CAPÍTULO I: IDENTIFICACIÓN DEL PROBLEMA .........................

CAPÍTULO II: DESCRIPCIÓN DE LAS ACTIVIDADES REALIZADAS .......5

2.1 Marketing Digital ...............................................5

2.2 Redirección de Servicios ...........................................6

3.3 Motivación en la empresa.........................................8

CAPÍTULO III: RESULTADOS DE LA INTERVENCIÓN .......................

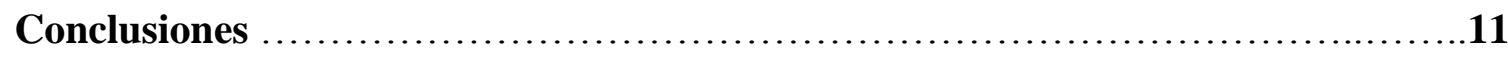

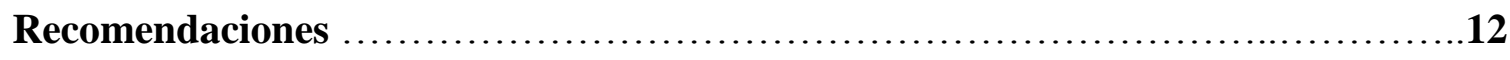

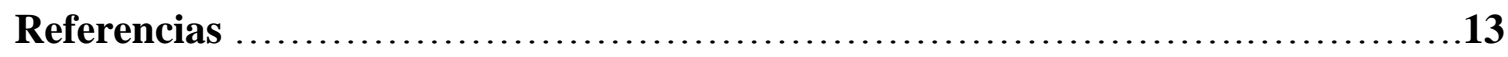

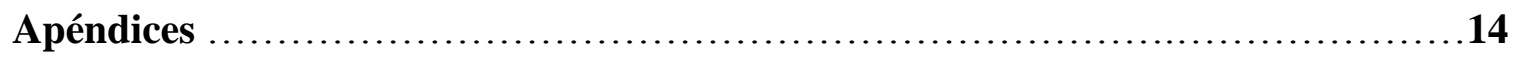




\section{ÍNDICE DE FIGURAS}

Figura 1: Cantidad de Requerimientos por Mes .......................................................... 3 


\section{ÍNDICE DE APÉNDICES}

Apéndice 1: Entrevista.................................................... 


\section{INTRODUCCIÓN}

El deporte y la psicología suelen estar más unidos de lo que muchas personas admiten. Es una realidad que el fútbol genera una suerte de colectivismo, además de romper las barreras que tanto nos diferencian en el día a día como el nivel sociocultural y económico (Moran y Toner, 2018). En función a las repercusiones que el mundial puede traer consigo, tenemos claro que existen tanto consecuencias positivas como negativas. La marca que genera el movimiento empresarial en fechas cercanas al campeonato es realmente considerada un estado de crisis (Salgado-Barandela, Barajas y Sánchez-Fernández, 2017). Un momento de cambios donde se ponen a prueba todos y cada uno de los organismos que conforman una institución para enfrentar y solucionar potenciales situaciones conflictivas de maneras creativas y óptimas. Como veremos en el presente trabajo, $\mathrm{T}$, una consultora de recursos humanos pequeña y muy entusiasta, supo manejar dicho escenario de forma heroica y ejemplar, dejando atrás prejuicios y suposiciones que, al contrario de desmotivarla, la hicieron más fuerte y capaz de confrontar todo lo que el mundial de fútbol trajo consigo. La explicación del problema, las tareas y actividades aplicadas al cambio y las recomendaciones hacia futuras situaciones similares, poco pueden expresar el sentimiento de compromiso y fidelidad reflejados en cada uno de los miembros del equipo hacia su querido centro de labores. Y a pesar de no ser el tema central de este documento, cabe resaltar que ese nivel de identificación institucional solo se logra luego de generar un excelente clima y una fuerte cultura organizacional que guíe a las tropas por un mismo camino, sin limitar la individualidad. 


\section{CAPÍTULO I: IDENTIFICACIÓN DEL PROBLEMA}

Una organización tiende a pasar por etapas de crisis y cambios que pueden generar situaciones conflictivas y problemáticas (Rodríguez y Mejía, 2018). En este caso, los miembros del equipo deben estar preparados para afrontar cualquiera de estas eventualidades y tratar de minimizar los daños y consecuencias negativas que puedan atacar la integridad de la institución. Siempre que el asunto en cuestión sea claro y preciso, las acciones a tomar suelen ser, a su vez, exactas y mesuradas. Cabe resaltar que, cuando un obstáculo se presenta de manera repetida a lo largo del tiempo de vida de la empresa, se genera una especie de patrón y esto puede significar que existen ya, opciones viables para solucionar la dificultad (Rodríguez y Mejía, 2018). Pero, como es en esta oportunidad, a veces se da un contratiempo "nuevo" o "singular" que afecta a todos los involucrados y los toma desprevenidos, en cuyo caso se debe tomar acción de manera creativa y rápida para optimizar tiempos y perder lo menos posible.

En la actualidad, y podemos sospechar que desde hace miles de años, el deporte es parte importante de todos los seres humanos (Elias y Dunning, 2014). Hay quienes viven de él, quienes lo practican como hobbie y quienes solo lo admiran desde lejos sin anhelar participación activa (Elias y Dunning, 2014). El fútbol es considerado uno de los deportes más representativos de nuestro país (Rodríguez, 2018). Significa cultura, unidad y colectividad, trabajo en equipo, perseverancia y motivación, liderazgo y tolerancia a la frustración, entre otras características que son fáciles de encontrar también en distintos sistemas como los negocios empresariales, las industrias y los centros educativos (Rodríguez, 2018).

Dentro de este marco, T (Consultora de RRRHH especializada en reclutamiento y selección) pasó por una significativa recesión económica a inicios del segundo semestre del 2018, fecha que coincide con el principio del campeonato mundial de fútbol en el que nuestro país participó luego de haber estado sentado en la banca por más de treinta años. Las repercusiones a nivel 
de reclutamiento y selección fueron catastróficas. En el periodo de enero a mayo, las ventas de este servicio fluctuaban de diez a veinte requerimientos por mes. Sin embargo, en los meses de junio, julio y agosto, el promedio bajó a cinco. Esto se expresa de manera visual en la siguiente figura:

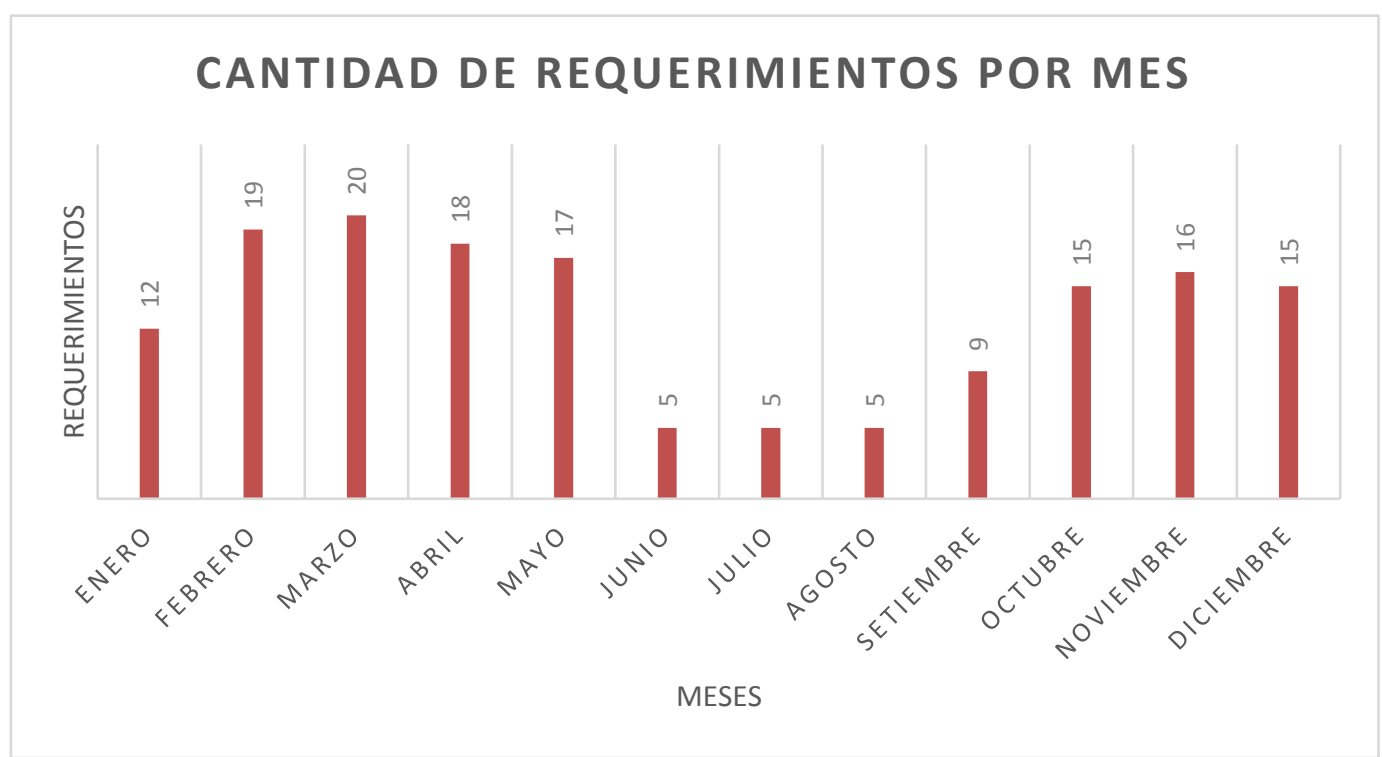

Figura 1. Comparativo de los requerimientos mensuales del servicio de reclutamiento y selección en el año 2018.

Las principales causas identificadas para este problema ocurrido en el margen de unos tres meses, aproximadamente, son las siguientes: 1 . La falta de interés por contratar personal nuevo. Las empresas se encontraban más dedicadas a atender asuntos referidos al mundial como sorteos para sus empleados o clientes, marketing acorde al deporte y posicionamiento de su marca aprovechándose de la euforia colectiva que se propagaba de manera viral en esas fechas (Sainz, 2018). 2. La falta de presupuesto para adquirir empleados calificados permanentes. Los grandes directivos estaban mucho más enfocados en contratar personal temporal para campañas y reemplazos (muchos viajaron a presenciar el mundial en vivo), que en invertir tiempo y dinero en todo lo que un proceso de selección supone, como entrevistas por competencias y exámenes 
psicolaborales $^{1}$. 3. La motivación y objetividad se vieron comprometidas. Los jefes, fanáticos del fútbol, estaban felices de que su país, por fin, participara en el mundial. Este estado de satisfacción momentánea desvió la parcialidad al evaluar el desempeño y rendimiento de los colaboradores, lo que produjo una calificación subjetiva guiada no por los resultados obtenidos, sino por el instinto de fraternidad y cultura colectiva generada de forma exagerada gracias a los muchos partidos de fútbol que vieron todos juntos en horarios de oficina usando la respectiva camiseta blanquiroja. En este punto se ve cómo, en vez de despedir al empleado poco capacitado y contar con el apoyo de una consultora especializada para buscar al profesional idóneo que cumpla con el perfil requerido, muchos optaron por retenerlo en base a lástima durante todo el periodo que se jugó el mundial, perdiendo así, valioso tiempo de trabajo $^{2}$.

Como un problema secundario, tenemos que los miembros del equipo $\mathrm{T}$, se desmotivaron considerablemente y hubo que hallar alternativas laborales para todos esos días de inactividad. La productividad en función al servicio de reclutamiento y selección fue muy baja y el daño colateral se reflejó incluso en la salud psicológica de algunos colaboradores que presentaban síntomas de desgano y falta de involucramiento. Algunos de ellos, faltaban al trabajo de manera injustificada ya que pensaban que su tiempo tendría mejor valor de inversión si se dedicaban a mirar el fútbol en vez de asistir a cumplir su deber.

\footnotetext{
${ }^{1}$ Entrevista realizada a un cliente recurrente de $\mathrm{T}$ (ver anexo 1 ).

${ }^{2}$ Entrevista realizada a un cliente recurrente de $\mathrm{T}$ (ver anexo 1 ).
} 


\section{CAPÍTULO II: DESCRIPCIÓN DE LAS ACTIVIDADES Y TAREAS REALIZADAS}

Dentro del contexto empresarial, existen diversas formas de alcanzar los objetivos y, por ende, de solucionar problemas (Rodríguez y Mejía, 2018). Las instituciones suelen contar con parámetros ya establecidos para afrontar situaciones que puedan comprometer la integridad del equipo y debilitar el cumplimiento de las metas en común (Rodríguez y Mejía, 2018). Siendo $\mathrm{T}$ una empresa joven con poca trayectoria en el mercado, afirmamos que dichas políticas proactivas de disminución de impacto frente a conflictos no existen o se encuentran en proceso de adaptación. Esto sugiere que la toma de decisiones ante una incógnita no siempre es la más adecuada o tendrá los mejores resultados. Sin embargo, la calidad humana que conforma T garantiza la intención más creativa y motivadora para sobrellevar dichos asuntos. Se detallarán, a continuación, algunas tareas realizadas para reducir la huella negativa que tuvo el mundial de fútbol en el inicio del segundo semestre del año 2018.

\subsection{Marketing Digital}

El marketing siempre ha sido una parte importante dentro de las empresas. La publicidad de los productos y servicios ofrecidos cumple un rol protagónico, pues, si no existe un mercado potencial, no se realiza la venta y, por ende, no se genera el negocio. Dentro de un marco globalizado como es en el nuestro, la oferta y demanda se encuentran digitalizadas, coexistiendo en un mundo virtual, donde inclusive los pagos se realizan mediante monedas cibernéticas (Sainz, 2018). No es para menos el motivo principal por el cual las organizaciones modernas deben mantenerse al tanto y tomar relevancia dentro de las redes sociales y el internet en general. T no fue una excepción. A partir del mes de mayo del 2018, T decidió contar con una persona encargada de 
manejar todas las redes digitales y promocionar los servicios que se ofrecen, además de renovar el logo y apoyar en la creación de diseños dinámicos para la realización de tarjetas de presentación. Todo esto con la finalidad de renovar la empresa y contrarrestar, en la medida de lo posible, la baja de trabajo durante los meses posteriores debido al mundial de fútbol ya antes mencionado.

\subsection{Redirección de Servicios}

La principal fuente de ingresos de T se deriva del servicio de reclutamiento y selección. Esto significa que al no contar con suficientes clientes que cubran esta necesidad mensual, la empresa se vio obligada en diversificar lo ofrecido al público. A finales del mes de mayo, notamos que empezaba a decaer el número de clientes que requerían nuevo personal permanente. Es decir, empleados capacitados con experiencia para distintos rubros y áreas. Lo que sí necesitaban las instituciones eran personas que cumplieran roles más pequeños y participaran en campañas dirigidas al mundial de fútbol como, por ejemplo: posiciones "chatas" (de baja o nula experiencia laboral) en ventas, anfitrionaje y activación de productos. Este tipo de perfiles es denominado "masivo" y suele tener una alta rotación debido a las funciones poco aplicadas a una carrera específica, a los horarios rotativos y a la contratación fuera de planilla. Por lo general, $\mathrm{T}$ rechaza todo tipo de requerimiento masivo, pero para lograr mantenerse a flote, fue necesario optar por esta alternativa durante algunos meses mientras se superaba la crisis económica generada por el mundial. La acción principal fue capacitar, rápidamente, al personal de $\mathrm{T}$ con algunas técnicas de reclutamiento y selección para puestos masivos y alcanzar los objetivos del mes a mes. La capacitación fue otorgada por un profesional especialista en temas de ventas, planes estratégicos y reclutamiento y selección. Se realizó de la siguiente manera: 
Actividades:

1. Charla sobre técnicas de reclutamiento masivo: el capacitador dedicó un par de horas a demostrar los beneficios de un reclutamiento masivo y cómo debe realizarse para obtener los mejores resultados en el menor tiempo posible con un mínimo margen de reposición del empleado.

2. Actividad de simulacro de trabajo: Bajo la supervisión de nuestro coach, todos alcanzamos un buen resultado luego de realizar un programa piloto en el que había que completar una cierta cantidad de requerimientos para un perfil de personal de seguridad (masivo).

3. Actividad de integración y autoconocimiento: El profesional a cargo nos invitó a conocernos como equipo para aprender a valorar las habilidades que cada uno tiene como persona y poder sacarles provecho según los clientes y requerimientos que surgieran. Se llegó a la conclusión de que algunos de nosotros somos más rápidos en conseguir ciertos perfiles que otros gracias a una serie de juegos y conversatorios que se llevaron a cabo. Para esto se realizaron dinámicas y juegos como: "charadas", donde un voluntario interpreta a un personaje y el resto del grupo debe adivinar cuál es y “confianza en el grupo", donde un miembro del equipo es guiado a través del salón por el resto del grupo, mientras tiene los ojos vendados.

Todos los miembros del equipo, logramos captar la estrategia y pudimos aplicar nuestro conocimiento y experiencia para crear un servicio novedoso y de eficaz que garantizara la satisfacción del cliente. 


\subsection{Motivación en T}

$\mathrm{T}$ es una organización que busca la constante armonía laboral. Está sumamente interesado en contar con trabajadores felices, motivados y muy leales. A nivel de motivación, específicamente, lo que se pretende es que todos estén siempre muy involucrados en cada proceso de reclutamiento y selección que se haga. Existe una constante comunicación con el cliente directo, las entrevistas realizadas a los postulantes siguen un criterio propio de cada evaluador y el trato hacía el jefe del área es horizontal lo que permite una comunicación fluida y una seria consideración de opiniones. Durante el inicio del segundo semestre del año 2018, la escasez de trabajo generó cierto nivel de aburrimiento y desmotivación. Una de las medidas tomadas fue buscar ocupar el tiempo libre en tareas a las que se les suele dar menos importancia por no considerarse rentables como la celebración de cumpleaños de los colaboradores o el aniversario de la empresa. Se aprovecharon varios días para realizar dichas actividades, incluyendo un paseo de integración que ya venía siendo postergado por meses debido a la gran carga laboral que imposibilitaba la salida de la oficina. Por otro lado, se propuso la opción de asistir a trabajar usando ropa casual que incluía la camiseta representativa del fútbol de nuestro país para así, disfrutar todos juntos de los partidos que pasaban en horarios laborales. Todas estas nuevas formas de convivencia tomaron un rol protagónico, sin dejar de lado a aquellos clientes que aún necesitaban los servicios de T como consultora de RRHH. 


\section{CAPÍTULO III: RESULTADOS DE LA INTERVENCIÓN}

En este apartado analizaremos los resultados obtenidos a partir de las tareas y actividades puestas en marcha para sobrellevar la crisis económica y motivacional que azotó a T dentro de un contexto deportivo con fuertes implicancias culturales.

En función al Marketing Digital, todo el equipo que conforma T, demostró tener gran apertura a la innovación, así como adaptación al cambio y aceptación a una Community Manager propuesta por mí según experiencias previas en anteriores empleos. Esta nueva adición a la empresa trajo consigo beneficios innumerables como: 1. La renovación de la página web. En los meses anteriores, el número de visitas que tenía la página era mínimo. Sin embargo, a partir de las mejoras realizadas, muchas empresas y postulantes se vieron más interesados en ingresar a explorar de manera virtual los servicios ofrecidos. 2. Una fuerte presencia a nivel de redes sociales. La Community Manager se mantuvo al tanto de todas las tendencias actuales en cuanto a publicidad en estos medios $\mathrm{y}$, hasta la fecha, $\mathrm{T}$ cuenta con un gran porcentaje de respuestas rápidas en Facebook ante consultas, publicación de ofertas laborales diarias y posteo de tips para los futuros candidatos. 3. El rediseño de las tarjetas de presentación y el logo de la empresa. Con la experiencia y creatividad que tiene la Community Manager y bajo mi supervisión (por órdenes de la gerencia, dada la confianza impuesta en mí y mi comprobado excelente ojo crítico), se mandaron a hacer nuevas tarjetas con un nuevo logo de T (también diseñado por ella) lo que generó un mayor impacto ante los clientes y una excelente primera impresión. Muchos de nuestros compradores regulares hicieron hincapié en lo novedoso que se veía nuestro cambio y aplaudieron el mismo, otorgándonos, siempre, todo su apoyo y respaldo.

En cuanto a la redirección de servicios, podemos afirmar que T disminuyó su porcentaje de requerimientos individuales, para entrar a competir en un mercado de posiciones masivas y 
perfiles de todo tipo. Además, han ido aumentando, considerablemente, las ventas por el servicio de capacitación y talleres para postulantes sobre redacción de CV y tips para entrevistas. Esto ha generado un nuevo abanico de posibilidades en cuanto a ingresos para la empresa.

Por último, para todos los colaboradores de $\mathrm{T}$ fue muy importante participar de aquellas actividades que generaron motivación y compañerismo, razón por la cual se ha decidido mantener ciertas tradiciones como la celebración de los cumpleaños y un paseo anual integrativo con la intención de sostener dichos estándares de felicidad en el trabajo que solo traen como consecuencia un mejor rendimiento. Esto podría propiciar la creación, a futuro, de nuevos planes estratégicos en el área de Cultura y Clima.

Tolas las medidas tomadas para revertir la crisis ocurrida a inicios del segundo semestre del 2018 por causa del mundial de fútbol, fueron evaluadas en el transcurso de esos mismos meses y en fechas posteriores. Se considera muy importante tomar en cuenta que estos resultados ponen en evidencia la gran facilidad con la que cualquier situación, por más negativa que sea, se puede encaminar hacia un bien común y un objetivo empresarial firme si se cuenta con la motivación y un fidelizado grupo humano, y no tanto con una enorme compañía y recursos ilimitados, como muchas veces se piensa (García, Lodoño y Ortiz, 2016).

La rama organizacional en psicología debe tomar en cuenta mucho más que la parte cuantitativa, ya que se trata de personas que cuentan con voluntad y valor propio, así como una mezcla de personalidades tratando de encajar entre ellas. Esto sugiere un gran nivel de subjetividad y no por eso es menos valioso. Se considera necesario y muy importante que, en un futuro, se utilicen herramientas menos tangibles y más enfocadas en el ser humano para evaluar y modificar conductas que permitan una excelente solución de situaciones extraordinarias y lleven al éxito laboral. 


\section{CONCLUSIONES}

- Gracias a las sugerencias dadas por los miembros del equipo y la aprobación de la gerencia, T contrató a una Community Manager para encargarse de las mejoras organizacionales a nivel virtual. Hasta le fecha, el cambio es notorio y la mejora, sustancial y fructífera.

- Se mejoró la página web de la empresa, incluyendo los nuevos servicios otorgados: reclutamiento masivo, capacitaciones y talleres.

- Se modernizaron los espacios dentro de las redes sociales: Facebook y linkedin, logrando incrementar, considerablemente, el número de requerimientos gracias a la gran llegada que tienen estas plataformas hacia los potenciales clientes.

- Se rediseñó el logo de T con una imagen más fresca y novedosa. Esto permitió posicionar a la empresa como una fuerte competidora en el mercado.

- Las tarjetas de presentación de todo el personal fueron renovadas acorde al nuevo logo de la empresa. Así, el sentido de identidad y pertenencia hacia T se fortaleció y esto generó un mejor rendimiento.

- Al agregar el servicio de reclutamiento masivo como parte de lo que T ofrece, se incrementó la productividad en el área de reclutamiento y selección. Asimismo, se vio disminuida la desmotivación ya que la atención estaba centrada en obtener el mejor performance posible en esta nueva función.

- Se propuso la opción de asistir a trabajar usando la camiseta representativa del Perú durante los días que hubiera partido para generar empatía entre los miembros del equipo.

- Se instauró la tradición de celebrar los cumpleaños de los colaboradores, además de contar con un paseo de integración anual. Esto para propiciar el compañerismo y la armonía dentro del lugar de trabajo. 


\section{RECOMENDACIONES}

- Toda empresa que pretenda crecer dentro del mercado actual debería contar con algún experto que otorgue su apoyo a nivel virtual.

- Sería necesario contar con una plataforma propia actualizada y moderna que integre todos los servicios que ofrece la empresa, así como una breve explicación de su historia, misión y visión para empatizar con aquellos que la visiten.

- Es importante contar con presencia en las redes sociales ya que los negocios suelen moverse en ese ambiente de manera más rápida.

- Se recomienda mantener actualizado el logo de la empresa ya que representa su marca y da la primera impresión ante un potencial cliente.

- Todo el personal debería estar alineado a la cultura de la organización. Esto incluye contar con herramientas que generen un buen primer impacto como las tarjetas de presentación.

- Se sugiere una constante investigación de mercado para poder ampliar los servicios que se brindan y llegar a cumplir con todas las necesidades del cliente.

- Como parte del código de vestimenta para el trabajo, se recomienda ampliar las opciones, particularmente en fechas especiales, para así generar un mayor vínculo de fidelización del empleado.

- Se recomienda contar con espacios de entretenimiento y esparcimiento, libres de carga laboral, para despejar la mente, integrarse como equipo y conocerse. Así se potenciarán los lazos entre los miembros y se obtendrán mejores resultados a nivel profesional. 


\section{REFERENCIAS}

Moran, A., y Toner, J. (2018). Psicología del deporte (3ºd.). México: El Manual Moderno.

Rodríguez, G., y Mejía, M. (2018). Uso de redes sociales corporativas en el manejo de crisis de una organización. (Artículo de especialización). Universidad Autónoma del Caribe.

Elias, N., y Dunning, E. (2014). Deporte y ocio en el proceso de la civilización (3 ed.). Mexico: Fondo de Cultura Económica.

Rodríguez, J. (2018). Héroes del 81. El camino invicto de la selección peruana hacia el mundial de España 82. Perú: Universidad Peruana de Ciencias Aplicadas.

Sainz, J. (2018). El plan de marketing digital en la práctica. ( $3^{\circ}$ ed.). Madrid: ESIC Editorial.

García, D., Lodoño, C., y Ortiz, L. (2016). Factores internos y externos que inciden en la motivación laboral. Revista electrónica Psyconex psicología, psicoanálisis y conexiones. Recuperado el 17 de febrero de 2019, de https://aprendeenlinea.udea.edu.co/revistas/index.php/Psyconex/article/view/326981

Salgado-Barandela, J., Barajas, A., y Sánchez-Fernández, P. (2017). Impacto económico del deporte: Tema de interés creciente en la literatura científica. Revista Internacional de Medicina y Ciencias de la Actividad Física y del Deporte. Recuperado el 17 de febrero de 2019, de https://repositorio.uam.es/handle/10486/680729 


\section{APÉNDICES}




\section{APÉNDICE 1: ENTREVISTA}

Transcripción de la entrevista realizada al Supervisor del área de Recursos Humanos de una empresa Retail, cliente frecuente de $\mathrm{T}$

1. ¿Cómo está afectando, económicamente, el mundial del fútbol a tu empresa?

- Bueno, creo que al igual que todas las empresas a nivel Perú, hemos entrado en una especie de recesión y crisis.

2. En general, ¿están contentos con el servicio de reclutamiento y selección ofrecido por T?

- Sí, bastante satisfechos. Son una empresa dedicada que brinda un servicio muy personalizado. Cumplen con la calidad y tiempo ofrecidos.

3. ¿Cuál es el motivo por el cual no han vuelto a realizar requerimientos de personal en el último mes (junio)?

- Bueno, como te dije, el mundial de fútbol ha hecho que nos desviemos un poco de la parte de selección y tomemos más acción a otros temas como el marketing y la integración de personal interno.

4. ¿Esto significa que ya no van a realizar nuevas contrataciones durante lo que dure esta crisis?

- En principio, esperamos que todo vuelva a la normalidad en unos 3 meses máximo. Pero, sí pretendemos adquirir nuevo personal, sólo que esta vez, necesitamos personas con un perfil más operativo que nos apoye en campañas y lanzamiento de productos. No podemos permitirnos, por el momento, contratar profesionales en el área administrativa ni capacitar a los que ya tenemos. Es un tema de optimizar tiempos.

5. ¿Estarías dispuesto a tomar en cuenta a $\mathrm{T}$ para realizar esta búsqueda de perfiles chatos que requiere tu empresa?

- No sabía que ustedes también hacían procesos masivos. Tendrían que enviarme una cotización para proponerlo a la directiva de la empresa que se encarga de este presupuesto. Pero en cuanto a la calidad de los psicólogos que trabajan en $\mathrm{T}$, tengo ya bastante garantía de un buen resultado.

6. ¿Qué hay de aquellos colaboradores que no están teniendo un buen rendimiento? ¿no sería conveniente reemplazarlos por unos más capacitados?

- La verdad es que creo que estamos pasando, como país, por un proceso de unificación, de cultura colectivista. No seríamos capaces de realizar despidos por bajo rendimiento a menos a que se trate de algo que afecte demasiado la productividad de la empresa. Si hablamos de unos cuantos informes entregados fuera de fecha o de ventas que no cumplieron la cuota establecida por un mínimo margen, entonces no hay problema. Siempre tratamos mejorar como empresa y lo vamos a seguir haciendo, pero repito: Nuestros esfuerzos están enfocados en otras cosas en estos momentos y ya retomaremos esas mejoras de personal en unos meses próximos. 